\title{
REMEDIAÇÃO DE DRENAGEM ÁCIDA DE MINA USANDO ZEÓLITAS SINTETIZADAS A PARTIR DE CINZAS LEVES DE CARVÃO
}

Denise Alves Fungaro* e Juliana de Carvalho Izidoro

Centro de Química e Meio Ambiente, Instituto de Pesquisas Energéticas e Nucleares, CP 11049, 05422-970 São Paulo - SP, Brasil

Recebido em 30/6/05; aceito em 28/9/05; publicado na web em 18/4/06

\begin{abstract}
REMEDIATION OF ACID MINE DRAINAGE USING ZEOLITES SYNTHESIZED FROM COAL FLY ASH. Zeolitic material was synthesized from coal fly ashes (baghouse filter fly ash and cyclone filter fly ash) by hydrothermal alkaline activation. The potential application of the zeolitic product for decontamination of waters from acid mine drainage was evaluated. The results showed that a dose of $30 \mathrm{~g} \mathrm{~L}^{-1}$ of zeolitic material allowed the water to reach acceptable quality levels after treatment. Both precipitation and cation-exchange processes accounted for the reduction in the pollutant concentration in the treated waters.
\end{abstract}

Keywords: zeolitic material; acid mine drainage; remediation.

\section{INTRODUÇÃO}

O carvão mineral é a maior fonte de energia não renovável no país. As maiores reservas de carvão estão localizadas no Rio Grande do Sul, Santa Catarina e Paraná com 28,8 bilhões, 3,4 bilhões e 100 milhões de $t$, respectivamente ${ }^{1}$. Os principais impactos ambientais produzidos durante as etapas de lavra e beneficiamento do carvão decorrem da disposição de resíduos sólidos estéreis e rejeitos, constituídos basicamente por materiais carbonosos e minerais (pirita e argilominerais) sem valor comercial, que são depositados em áreas próximas ao local de mineração.

Estes estéreis e rejeitos ricos em sulfetos de ferro oxidam-se em presença do ar, da água e da ação de bactérias Thiobacilus ferroxidans, desencadeando o processo de acidificação de drenagens e a dissolução de metais, que pode ocorrer em minas abandonadas ou em operação, originando a drenagem ácida de mina (DAM). O nível de acidez, a concentração e a composição dos metais da DAM dependem do tipo e quantidade de sulfetos e da presença ou ausência de materiais alcalinos. Em conseqüência desse fenômeno, além do risco de contaminação de fontes de água superficiais e subterrâneas com a possível destruição do habitat aquático, a recuperação dessas áreas se torna mais cara devido à maior dificuldade de reflorestamento.

O carvão extraído em minas a céu aberto e subterrâneas é enviado às usinas de beneficiamento e gera cerca de $60 \%$ de resíduos sólidos e aproximadamente $1,5 \mathrm{~m}^{3}$ de efluentes ácidos para cada tonelada lavrada. No ano de 2000 foram gerados cerca de 4 milhões de $t$ de rejeitos e estéreis do carvão beneficiado nas carboníferas brasileiras ${ }^{1}$.

As reações químicas que explicam a oxidação da pirita e a produção de ácido in situ são representadas pelas seguintes Equações²

$$
\begin{aligned}
& \mathrm{FeS}_{2}(\mathrm{~s})+7 / 2 \mathrm{O}_{2}(\mathrm{~g})+\mathrm{H}_{2} \mathrm{O}(\mathrm{l}) \longleftrightarrow \mathrm{Fe}^{2+}(\mathrm{aq})+2 \mathrm{SO}_{4}^{2-}(\mathrm{aq})+2 \mathrm{H}^{+}(\mathrm{aq}) \\
& \mathrm{Fe}^{2+}(\mathrm{aq})+1 / 4 \mathrm{O}_{2}(\mathrm{~g})+2 \mathrm{H}^{+}(\mathrm{aq}) \longleftrightarrow \mathrm{Fe}^{3+}(\mathrm{aq})+\mathrm{H}_{2} \mathrm{O} \\
& \mathrm{Fe}^{3+}(\mathrm{aq})+3 \mathrm{H}_{2} \mathrm{O}(\mathrm{l}) \longleftrightarrow \mathrm{Fe}(\mathrm{OH})_{3}(\mathrm{~s})+3 \mathrm{H}^{+}(\mathrm{aq}) \\
& 4 \mathrm{FeS}_{2}(\mathrm{~s})+15 \mathrm{O}_{2}(\mathrm{~g})+14 \mathrm{H}_{2} \mathrm{O}(\mathrm{l}) \longleftrightarrow \mathrm{Fe}(\mathrm{OH})_{3}(\mathrm{~s})+ \\
& 8 \mathrm{SO}_{4}^{2-}(\mathrm{aq})+16 \mathrm{H}^{+}(\mathrm{aq})
\end{aligned}
$$

*e-mail: dfungaro@ipen.br
O íon ferroso gerado na reação (Equação 1) pode ser oxidado ao estado férrico (Equação 2) que se hidroliza gerando mais acidez (Equação 3). As bactérias catalisam a reação de oxidação da etapa 2. Os hidróxidos ferrosos e férricos, associados na reação química da Equação 2, dão a cor vermelha-alaranjada que é característica da drenagem ácida de mina e pode ser observada geralmente nos corpos d'água das áreas de mineração de carvão. Uma vez que os produtos da oxidação estão na solução, a etapa que determina a reação ácida é a oxidação do íon ferroso $\left(\mathrm{Fe}^{2+}\right)$ ao íon férrico $\left(\mathrm{Fe}^{3+}\right)$. Os produtos solúveis da oxidação da pirita são removidos pela água; conseqüentemente, na ausência de materiais alcalinos, as reações de produção de ácidos podem prosseguir por períodos indefinidos de tempo.

Estudos realizados nos EUA mostraram os seguintes fatos: a DAM chega a afetar cerca de $23000 \mathrm{~km}$ de cursos d'água ${ }^{3}$; uma típica mina abandonada requer o tratamento de quase 3 milhões de $\mathrm{m}^{3}$ de DAM por ano ${ }^{4}$; o efeito nocivo da DAM foi observado em minas abandonadas há mais de 100 anos.

O problema da poluição causado por DAM no Brasil tem sido notificado em várias regiões carboníferas do sul. Três bacias hidrográficas do Estado de Santa Catarina são consideradas impactadas pela atividade mineradora de carvão: a Bacia do Rio Araranguá, do Rio Tubarão e do Rio Urussanga.

No circuito das águas da Indústria Carbonífera Rio Deserto do Sistema Mina do Trevo, em Santa Catarina, foram avaliadas 29 áreas em atividades de mineração constatando-se que a maioria das instalações não possui qualquer tipo de remediação e houve uma piora na qualidade das águas entre 2002 e $2003^{5}$.

Uma situação muito grave de danos à agricultura, pecuária e saúde da população local foi relatada em 2004, em Capivari de Baixo (SC), provocada pelos efluentes de mineração da usina termelétrica Jorge Lacerda ${ }^{6}$.

Os rejeitos provenientes da lavra e do beneficiamento das minas de carvão de Figueira (PR), que são objetos deste estudo, cobrem uma área de $0,4 \mathrm{~km}^{2}$. Tendo em vista o quadro mostrado acima, são necessários monitoramentos e investimentos constantes para minimizar os danos ambientais provocados pelos efluentes de mineração.

A DAM contém íons metálicos dissolvidos (As, $\mathrm{Cd}, \mathrm{Cu}, \mathrm{Ni}, \mathrm{Pb}$, $\mathrm{Zn}, \mathrm{Al}, \mathrm{Cr}, \mathrm{Mn}, \mathrm{Mg}$, etc), em composições e concentrações que dependem de condições geológicas específicas. As múltiplas combinações de acidez e íons metálicos fazem com que cada efluente de 
mineração seja único e, portanto, o tratamento adequado varie de sítio para sítio.

Existem vários métodos de tratamento de DAM utilizados para alcançar os níveis de descarga de poluentes permitidos pela legislação do Conselho Nacional do Meio Ambiente - Resolução CONAMA $357 / 2005^{7}$. A melhor entre as alternativas dependerá de fatores técnicos (volume de efluentes, tipo e concentração dos contaminantes presentes, etc) e econômicos ${ }^{8-9}$.

Os sistemas de tratamentos convencionais envolvem neutralização e precipitação pela adição de substâncias alcalinas, como pedra calcária, lima, hidróxido ou carbonato de sódio. As desvantagens desta tecnologia são a produção de grandes quantidades de lodo, que devem ser dispostas de maneira adequada envolvendo altos custos; a necessidade de uma grande dose de material alcalino para manter o pH acima de 6,5 e os íons metálicos presentes na DAM não são recuperados.

A adsorção é um dos métodos que pode ser aplicado tanto para a remoção como para a recuperação dos íons metálicos do efluente ácido de mineração ${ }^{10-13}$. O carbono ativado tem sido usado como um adsorvente padrão mas, devido ao seu alto custo são desenvolvidas pesquisas focando materiais alternativos ${ }^{14}$.

Outro problema ambiental grave relacionado ao funcionamento de usinas termelétricas está relacionado com a produção de toneladas de cinzas de carvão e sua disposição inadequada causando contaminação do solo e das águas superficiais e subterrâneas. As principais aplicações das cinzas são na fabricação e incorporação ao cimento e uso como material fertilizante, mas isto ainda ocorre em pequena escala $(\sim 30 \%)$. Uma das maneiras de reduzir os impactos ambientais decorrentes da disposição destes resíduos consiste na ampliação de sua utilização, com a conseqüiente adição de valor agregado.

As cinzas de carvão mineral são constituídas basicamente de sílica e alumina, sendo possível convertê-las em material zeolítico após tratamento hidrotérmico em meio alcalino. As substâncias tóxicas que a cinza contém são removidas na solução básica que é encaminhada para tratamento ou re-aproveitamento posterior. O conteúdo de zeólita obtido varia entre 20-75\%, dependendo das condições da reação de ativação. O material zeolítico (ou zeólita sintética) pode ser utilizado como adsorvedor de baixo custo, apresentando capacidade de troca catiônica na faixa de 100 a 396 meq $100 \mathrm{~g}^{-1}$.

Em conjunto com o desenvolvimento de métodos de síntese, inúmeras pesquisas foram realizadas para encontrar as aplicações potenciais das zeólitas sintéticas na remoção de metais ${ }^{15-24}$. No entanto, há pouquíssimos estudos sobre esta alternativa empregando-se cinzas de carvão geradas no Brasil ${ }^{25-28}$. O carvão brasileiro apresenta uma proporção maior de matéria mineral que os carvões europeus e norte-americanos e um alto teor de cinzas $(45-60 \% \mathrm{~m} / \mathrm{m})$ e estas características irão influenciar as propriedades das cinzas e das suas respectivas zeólitas e, conseqüentemente, a capacidade de troca iônica do adsorvedor.

O objetivo deste estudo foi utilizar a zeólita preparada com cinzas de carvão no tratamento dos efluentes de mineração. Esta ação, se bem sucedida ajudará a solucionar dois problemas ambientais gravíssimos: o das águas ácidas geradas pelos rejeitos piritosos do carvão e o do acúmulo de cinzas da geração termelétrica.

\section{PARTE EXPERIMENTAL}

\section{Materiais e métodos}

Todos os reagentes foram de grau analítico (Merck) e as soluções estoques foram preparadas a partir da diluição com água ultrapura do sistema Millipore Milli-Q. Os experimentos foram realizados à temperatura de $25 \pm 1{ }^{\circ} \mathrm{C}$. Agitador mecânico com temperatura controlada e centrífuga foram utilizados.

\section{Preparação das zeólitas}

As cinzas de carvão da Usina Termelétrica de Figueira, localizada no Paraná, foram utilizadas no estudo. As zeólitas foram preparadas a partir dos seguintes tipos de cinzas leves: retidas no filtro manga $(\mathrm{ZM})$ e retidas no filtro ciclone $(\mathrm{ZC})$. O seguinte tratamento hidrotérmico foi realizado ${ }^{29}$ : a amostra contendo $30 \mathrm{~g}$ de cinzas de carvão foi colocada com $240 \mathrm{~mL}$ de $\mathrm{NaOH} \mathrm{3,5} \mathrm{mol} \mathrm{L}{ }^{-1}$ e aquecida em estufa, a $100{ }^{\circ} \mathrm{C}$, por $24 \mathrm{~h}$. A suspensão foi filtrada e o sólido foi repetidamente lavado com água deionizada e seco em estufa a $40^{\circ} \mathrm{C}$. As zeólitas foram analisadas por fluorescência de raios-X (XRFS RIX 3000 - Rigaku) e por difração de raios-X (Bruker-AXS D8). A capacidade de troca catiônica (CTC) dos materiais zeolíticos foi obtida usando solução de acetato de sódio e de amônio ${ }^{22}$.

\section{Processo descontínuo de adsorção}

Os processos descontínuos foram realizados por agitação de $1 \mathrm{~g}$ de zeólita com $100 \mathrm{~mL}$ da solução de $\mathrm{Zn}^{2+} \mathrm{e} \mathrm{Cd}^{2+}$ com concentração conhecida. O sobrenadante foi separado por centrifugação e a concentração do metal nesta solução foi determinada por titulação complexiométrica com EDTA. Os dados das isotermas foram obtidos após um tempo de equilíbrio de $24 \mathrm{~h}$. Os estudos foram realizados utilizando-se concentrações dos íons metálicos na faixa de 131-895 $m g \mathrm{~L}^{-1}$. Todos os experimentos foram realizados em duplicata.

As amostras de drenagem ácida foram coletadas na Usina Termelétrica de Figueira. Alíquotas de $100 \mathrm{~mL}$ de água ácida da mina (AAM) e da água ácida da pilha de rejeitos (APR) foram misturadas com doses de zeólita de 30 e $150 \mathrm{~g} \mathrm{~L}^{-1}$, respectivamente, estimadas a partir do conteúdo inicial de ferro. Após um tempo de contato de $24 \mathrm{~h}$, a mistura foi filtrada em membrana de filtro 0,45 $\mu \mathrm{m}$ (Millipore) e acidificada a $\mathrm{pH}<2$. A concentração dos elementos antes e após o tratamento com zeólita foi determinada por espectrometria de emissão com plasma indutivamente acoplado (Spectro M120 E).

\section{RESULTADOS E DISCUSSÃO}

\section{Características físico-químicas das zeólitas}

As composições químicas (em \% em massa) dos produtos zeolíticos obtidos com as diferentes cinzas de carvão estão apresentadas na Tabela 1. As zeólitas ZM e ZC apresentaram conteúdos de alumina e sílica muito similares $\left(\mathrm{SiO}_{2}+\mathrm{Al}_{2} \mathrm{O}_{3} 65-70 \%\right)$, conteúdo

Tabela 1. Composição química das zeólitas sintéticas do filtro manga (ZM) e do filtro ciclone (ZC)

\begin{tabular}{lcclcc}
\hline & Óxidos/\% & \multicolumn{3}{c}{ Elementos traço/ $\mu \mathrm{g} \mathrm{g}^{-1}$} \\
& $\mathrm{ZM}$ & $\mathrm{ZC}$ & & $\mathrm{ZM}$ & $\mathrm{ZC}$ \\
\hline $\mathrm{SiO}_{2}$ & 42,44 & 46,03 & $\mathrm{MnO}$ & 710 & 614 \\
$\mathrm{Al}_{2} \mathrm{O}_{3}$ & 25,66 & 24,18 & $\mathrm{PbO}$ & 644 & 523 \\
$\mathrm{Fe}_{2} \mathrm{O}_{3}$ & 13,76 & 12,58 & $\mathrm{Cl}$ & 252 & 241 \\
$\mathrm{Na}_{2} 0$ & 9,02 & 8,75 & $\mathrm{SrO}$ & 864 & 900 \\
$\mathrm{CaO}$ & 3,30 & 3,25 & $\mathrm{Cr}_{2} \mathrm{O}_{3}$ & 294 & 274 \\
$\mathrm{~K}_{2} \mathrm{O}$ & 1,26 & 0,91 & $\mathrm{P}_{2} \mathrm{O}_{5}$ & 657 & 633 \\
$\mathrm{TiO}_{2}$ & 1,43 & 1,26 & $\mathrm{CuO}_{2}$ & 156 & - \\
$\mathrm{SO}_{3}$ & 0,62 & 1,04 & $\mathrm{NiO}_{2}$ & 188 & 202 \\
$\mathrm{MgO}$ & 1,38 & 1,22 & $\mathrm{U}_{3} \mathrm{O}_{4}$ & 695 & 603 \\
$\mathrm{ZnO}$ & 0,39 & 0,18 & $\mathrm{Y}_{2} \mathrm{O}_{3}$ & 267 & 209 \\
$\mathrm{ZrO}_{2}$ & 0,19 & 0,16 & $\mathrm{As}_{2} \mathrm{O}_{3}$ & 729 & - \\
$\mathrm{SiO}_{2} / \mathrm{Al}_{2} \mathrm{O}_{3}$ & 1,65 & 1,90 & $\mathrm{Rb}_{2} \mathrm{O}_{3}$ & 43 & 35 \\
& & & $\mathrm{GeO}_{2}$ & 57 & - \\
\hline
\end{tabular}


relativamente alto de óxido férrico $(10-16 \%)$ e óxido de sódio (7$16 \%$ ). Encontraram-se os óxidos de cálcio, potássio, titânio, enxofre, magnésio e outros compostos em quantidades menores que $5 \%$.

A análise por difração de raios- $\mathrm{X}$ revelou que após o tratamento hidrotérmico das cinzas de carvão formou-se a zeólita NaP1 com traços de hidroxisodalita, enquanto quartzo e mulita também estavam presentes (Figura 1).

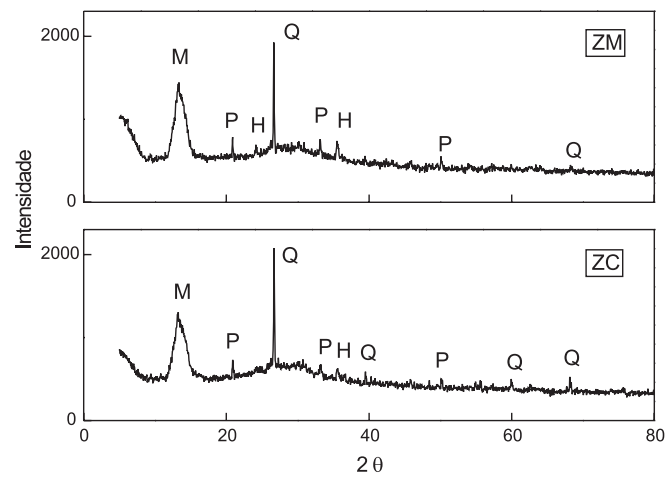

Figura 1. Difração de raios-X do material zeolítico preparado com cinza leve do filtro manga $(Z M)$ e cinza leve do filtro ciclone (ZC). $Q=$ quartzo; $M=$ mulita; $P$ = zeólita NaP1; $H$ = hidroxisodalita

Os valores de CTC encontrados foram 176,9 meq $100 \mathrm{~g}^{-1}$ para a ZM e 138,1 meq $100 \mathrm{~g}^{-1}$ para ZC. A comparação dos valores da capacidade de troca catiônica da zeólita sintética comercial NaP1 (500 meq $100 \mathrm{~g}^{-1}$ ) com aqueles encontrados com os produtos zeolíticos $\mathrm{ZM}$ e ZC indicou que o conteúdo de zeólita obtido na síntese hidrotérmica foi de 35,4 e 27,6\%, respectivamente. A área superficial específica (procedimento padrão $\mathrm{BET}$ - adsorção de $\mathrm{N}_{2}$ ) dos materiais zeolíticos apresentou valores entre $30-34 \mathrm{~m}^{2} \mathrm{~g}^{-1}$, similar aos dos materiais argilosos e caulinitas ${ }^{30-31}$.

\section{Efeito do tempo de contato}

As cinéticas de adsorção do efluente simulado contendo $\mathrm{Zn}^{2+} \mathrm{e}$ $\mathrm{Cd}^{2+}$ por material zeolítico foram estudadas por processos descontínuos, onde as concentrações dos íons metálicos foram determinadas após intervalos de tempo de agitação (Figura 2). A remoção foi rápida nos estágios iniciais de contato e gradualmente decresceu até atingir o equilíbrio. Os sistemas aproximaram-se do equilíbrio após $4 \mathrm{~h}$ na concentração inicial de 327 e $562 \mathrm{mg} \mathrm{L}^{-1} \mathrm{de} \mathrm{Zn}^{2+} \mathrm{e} \mathrm{Cd}^{2+}$, respectivamente, alcançando uma eficiência de remoção dos íons metálicos entre 70

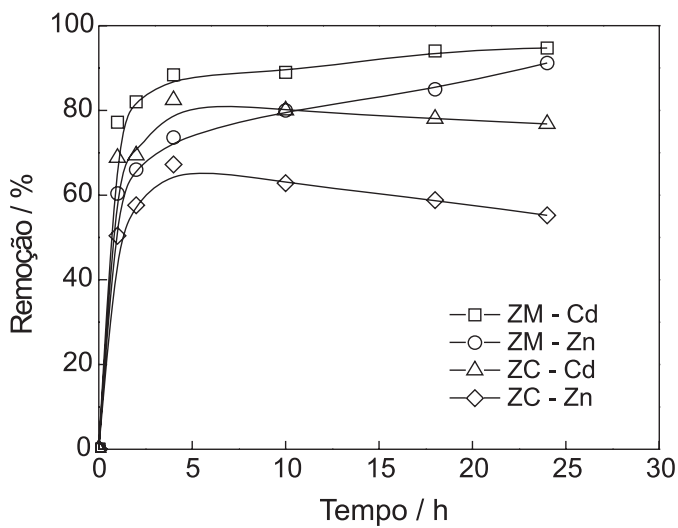

Figura 2. Efeito do tempo de agitação na remoção de $\mathrm{Zn}^{2+} e \mathrm{Cd}^{2+}$ pelas zeólitas $\mathrm{ZM}$ e $\mathrm{ZC}$ a 90\%. A forma simples e contínua das curvas até a saturação sugeriu uma cobertura por monocamada dos íons metálicos na superfície do adsorvedor.

\section{Isotermas de adsorção}

As isotermas de adsorção foram determinadas para o sistema metal-zeólita usando-se as equações de Langmuir e Freundlich, que são os modelos mais freqüentemente usados para descrever isotermas para aplicações em tratamento de águas e efluentes ${ }^{32,33}$. A Figura 3 mostra as isotermas de adsorção do Zn e Cd para a zeólita da cinza leve do filtro manga e para a zeólita da cinza leve do ciclone. As equações de Langmuir e Freundlich podem ser linearizadas e as constantes podem ser determinadas por regressão linear. Os parâmetros das isotermas encontrados para zinco e cádmio estão listados nas Tabela 2.

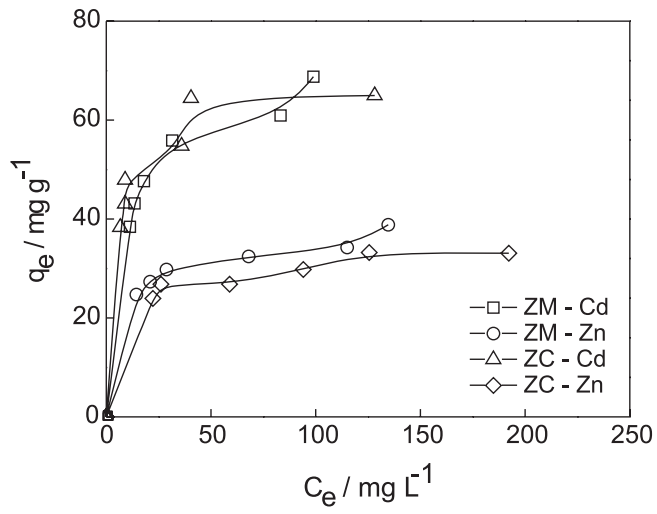

Figura 3. Isotermas de adsorção do $\mathrm{Zn}^{2+}$ e $\mathrm{Cd}^{2+}$ nas zeólitas $\mathrm{ZM}$ e ZC

Tabela 2. Parâmetros dos modelos de isoterma de Freundlich e Langmuir para $\mathrm{Zn}^{2+}$ e $\mathrm{Cd}^{2+}$ com as zeólitas $\mathrm{ZM}$ e $\mathrm{ZC}$

\begin{tabular}{lcccccc}
\hline Adsorvente & & \multicolumn{2}{c}{ Freundlich } & \multicolumn{3}{c}{ Langmuir } \\
& & $\mathrm{K}_{\mathrm{f}}^{*}$ & $\mathrm{n}$ & $\begin{array}{c}\mathrm{Q}_{\mathrm{o}} \\
\left(\mathrm{mg} \mathrm{g}^{-1}\right)\end{array}$ & $\begin{array}{c}\mathrm{b} \\
\left(\mathrm{L} \mathrm{mg}^{-1}\right)\end{array}$ & $\mathrm{R}_{\mathrm{L}}$ \\
\hline $\mathrm{ZM}$ & $\mathrm{Zn}$ & 17,41 & 6,89 & 36,09 & 0,15 & 0,012 \\
& $\mathrm{Cd}$ & 24,74 & 4,40 & 76,28 & 0,092 & 0,014 \\
& & & & & & \\
$\mathrm{ZC}$ & $\mathrm{Zn}$ & 14,88 & 6,64 & 35,12 & 0,082 & 0,023 \\
& $\mathrm{Cd}$ & 30,61 & 6,39 & 67,43 & 0,207 & 0,006 \\
\hline
\end{tabular}

$(*)\left(\mathrm{mg} \mathrm{g}^{-1}\right)\left(\mathrm{L} \mathrm{mg}^{-1}\right)^{1 / n}$

As isotermas de sistemas líquido/sólido podem ser classificadas de acordo com suas formas que são determinadas pelo mecanismo de adsorção e, portanto, esta classificação pode ser usada para diagnóstico da natureza da adsorção ${ }^{34}$. Nesta classificação qualitativa, as isotermas foram divididas em quatro classes principais que, por conveniência, usam o termo S, L (Langmuir), H (alta afinidade) e C (partição constante). Cada uma das classes foi subdividida de acordo com a presença de patamares, pontos de inflexão de máximo ou mínimo (subgrupos 1, 2, 3, 4 ou max).

As isotermas de $\mathrm{Zn}^{2+}$ e $\mathrm{Cd}^{2+}$ têm um comportamento concordante com o Tipo L2, no qual a afinidade de adsorção aumenta com o aumento da concentração do adsorvato até a saturação $0^{34}$.

As zeólitas ZM e ZC alcançaram capacidades de adsorção dos íons metálicos entre 35 a $76 \mathrm{mg} \mathrm{g}^{-1}$ e eficiência de retenção $\geq 70 \%$. Os adsorvedores que apresentam capacidade de adsorção $\geq 20 \mathrm{mg} \mathrm{g}^{-1}$ são 
considerados aceitáveis ${ }^{35}$. Os valores das constantes n $(2<\mathrm{n}<10)$ e $\mathrm{R}_{\mathrm{L}}\left(0<\mathrm{R}_{\mathrm{L}}<1\right)$ mostraram que o processo de adsorção é favorável para a faixa de concentração estudada ${ }^{36,37}$.

A zeólita ZM apresentou melhor eficiência de adsorção que ZC devido, principalmente, aos seguintes fatores: menor relação $\mathrm{SiO}_{2} / \mathrm{Al}_{2} \mathrm{O}_{3}$ na composição química da zeólita e conseqüente maior capacidade de troca catiônica e maior conteúdo de NaP1 formado na cinza modificada.

\section{Tratamento de efluentes ácidos de mineração}

Os efluentes ácidos de mineração foram amostrados na Usina Termelétrica de Figueira constituindo-se de água ácida da mina (AAM) e da água ácida da pilha de rejeitos (APR). O material zeolítico ZM foi usado no tratamento das amostras por apresentar capacidade de troca catiônica mais alta e um conteúdo maior de zeólita NaP1, induzindo um processo de troca iônica mais favorável. Os resultados dos testes de descontaminação encontram-se na Tabela 3.

Tabela 3. Características das amostras dos efluentes ácidos de mineração antes e depois do tratamento com zeólita

\begin{tabular}{lccccc}
\hline & \multicolumn{2}{c}{ AAM } & \multicolumn{2}{c}{ APR } & LMP \\
& antes & depois & antes & depois \\
\hline $\mathrm{pH}$ & 2,7 & 5,0 & 3,4 & 5,0 & $5-9$ \\
& \multicolumn{5}{c}{$\mathrm{mg} \mathrm{L}^{-1}$} \\
$\mathrm{~Pb}$ & 0,024 & $<0,001$ & $<0,001$ & $<0,001$ & 0,5 \\
$\mathrm{Cd}$ & 0,095 & 0,026 & 0,17 & 0,065 & 0,2 \\
$\mathrm{Mn}$ & 6,6 & 1,98 & 102,1 & 95,7 & 1,0 \\
$\mathrm{Zn}$ & 26,2 & 2,20 & 236,0 & 144,0 & 5,0 \\
$\mathrm{Fe}$ & 251,9 & 11,1 & 4608 & 3441 & 15 \\
$\mathrm{Cu}$ & 0,15 & 0,01 & 1,03 & 0,39 & 1,0 \\
$\mathrm{Cr}$ & 0,07 & 0,0004 & 0,0013 & 0,0004 & 2,5 \\
$\mathrm{As}$ & 0,044 & 0,002 & 0,002 & $<0,001$ & 0,5 \\
\hline
\end{tabular}

$\mathrm{AAM}=$ água ácida de mina; $\mathrm{APR}=$ água ácida da pilha de rejeitos; LMP = limite máximo permissível para efluentes segundo Resolução CONAMA $n^{\circ} .20^{7}$.

Uma redução substancial das concentrações de $\mathrm{Pb}, \mathrm{Cd}, \mathrm{Mn}$, $\mathrm{Cu}, \mathrm{Cr}$ e As foi obtida para a água ácida de mina (Figura 4a). O tratamento com a zeólita permitiu também que as altas concentrações de $\mathrm{Fe}$ e $\mathrm{Zn}$ atingissem os níveis aceitáveis de qualidade de água (Figura 4b), bem como o valor do $\mathrm{pH}$ final das soluções tratadas $(5,0)$. O aumento do $\mathrm{pH}$ final é muito importante já que a préneutralização do efluente, que é realizada normalmente em tratamentos convencionais, pode ser dispensada reduzindo o número de etapas de remediação e custos associados.

A redução nas concentrações dos íons metálicos na faixa de 70 a 99\% indicou que a dose de zeólita usada foi adequada para descontaminação do efluente (Figura 5). Uma dose similar de diferentes tipos de zeólitas sintetizadas a partir de cinzas de carvão (20$40 \mathrm{~g} \mathrm{~L}^{-1}$ ) foi considerada apropriada para tratamento das águas de um poço e de um rio altamente contaminados com água ácida de mina e lama de pirita, da região do vale Guadiamar, na Espanha ${ }^{38,39}$.

A seletividade da troca iônica para os íons metálicos é o resultado da competição entre os cátions principais e traços pela troca com $\mathrm{Na}^{+}$da estrutura da zeólita. A seguinte ordem de afinidade da zeólita pelos cátions estudados foi inferida a partir de uma avaliação qualitativa dos resultados: $\mathrm{Cr}>\mathrm{Pb}>\mathrm{Fe}>\mathrm{As}>\mathrm{Cu}>\mathrm{Zn}>\mathrm{Cd}>$ Mn. A precipitação de fases sólidas estáveis dos íons metálicos como hidróxidos ou sulfatos ocorre em conjunto com o processo principal de troca iônica, devido ao aumento de $\mathrm{pH}$ da solução pela
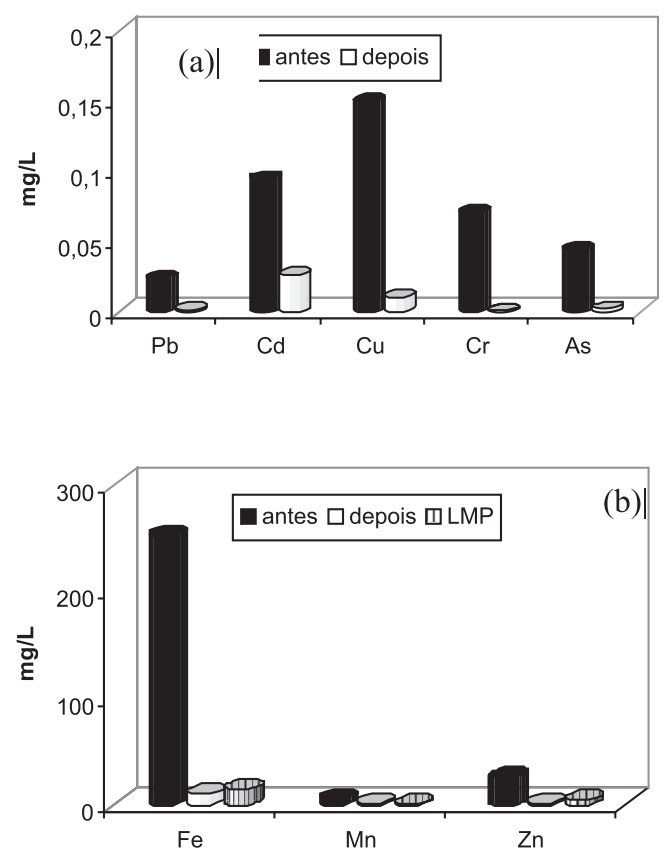

Figura 4. Concentração dos íons metálicos antes e depois do tratamento da água ácida de mina com material zeolítico: (a) concentração inicial 0,02 0,15 $\mathrm{mg} \mathrm{L}^{-1}$; (b) concentração inicial 6,6 - $252 \mathrm{mg} \mathrm{L}^{-1}$; LMP = limite máximo permissível para efluentes

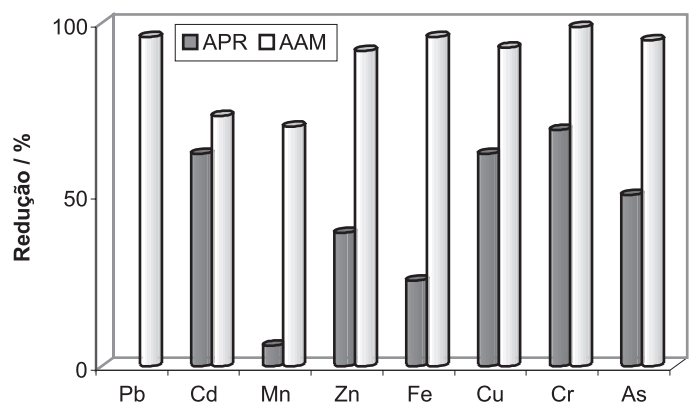

Figura 5. Porcentagens de redução dos íons metálicos da amostra de água ácida de mina (AAM) e água ácida da pilha de rejeitos (APR) após tratamento com material zeolítico

adição da zeólita e, com isso, a eficiência da remoção melhora, influenciando também a série de afinidade.

A afinidade de uma zeólita no processo de adsorção está relacionada com muitos fatores incluindo topologia da estrutura (configuração do canal e dimensões), tamanho e forma do íon metálico, densidade de carga nos canais, valência do íon metálico, dentre outros $^{40}$. Geralmente, as diferenças ocorrem devido ao tamanho do raio do íon metálico hidratado e ao valor da sua energia de hidratação. Os cátions em solução aquosa perdem parte de suas águas de hidratação para possibilitar sua entrada na estrutura da zeólita e, conseqüentemente, o acesso aos sítios de troca. Quanto maior for o raio do íon metálico hidratado e mais elevada for a energia de hidratação, mais difícil é para o íon entrar nos poros da zeólita para a reação de troca catiônica nos sítios disponíveis.

$\mathrm{O} \mathrm{Mn}^{2+}$ é desfavorecido no processo de adsorção porque seu raio hidratado e sua energia de hidratação são maiores em relação 
aos outros íons. Por outro lado, a remoção do $\mathrm{Mn}^{2+}$ por precipitação é um processo lento e também desfavorável, já que requer que o íon divalente seja oxidado aos estados +3 ou $+4^{9}$.

Os resultados para o tratamento da água ácida da pilha de rejeitos foram significantemente diferentes daqueles obtidos com a água ácida de mina, devido ao alto conteúdo de ferro inicial (4608 $\mathrm{mg} \mathrm{L}^{-1}$ ). $\mathrm{O} \mathrm{Fe}^{3+}$ tem alta afinidade pelos sítios de troca iônica do $\mathrm{Na}^{+}$da zeólita em relação à maioria dos metais divalentes e, conseqüentemente, as altas concentrações deste íon na amostra inicial reduzem as posições disponíveis para os íons metálicos restantes e não é possível a determinação de uma série de afinidade dos íons. Os melhores resultados foram alcançados com o pH final e com a concentração dos íons $\mathrm{Cd}^{2+}$ e $\mathrm{Cu}^{2+}$, que apresentaram valores dentro dos níveis exigidos para o descarte de efluentes após o tratamento (Figura 6a). A remoção não foi efetiva para os íons que estavam em níveis muito acima do limite máximo permissível (Figura 6b). Uma redução nas concentrações dos íons metálicos na faixa 6 a $69 \%$ foi alcançada após o tratamento com zeólita nas amostras de água ácida da pilha de rejeitos (Figura 5).
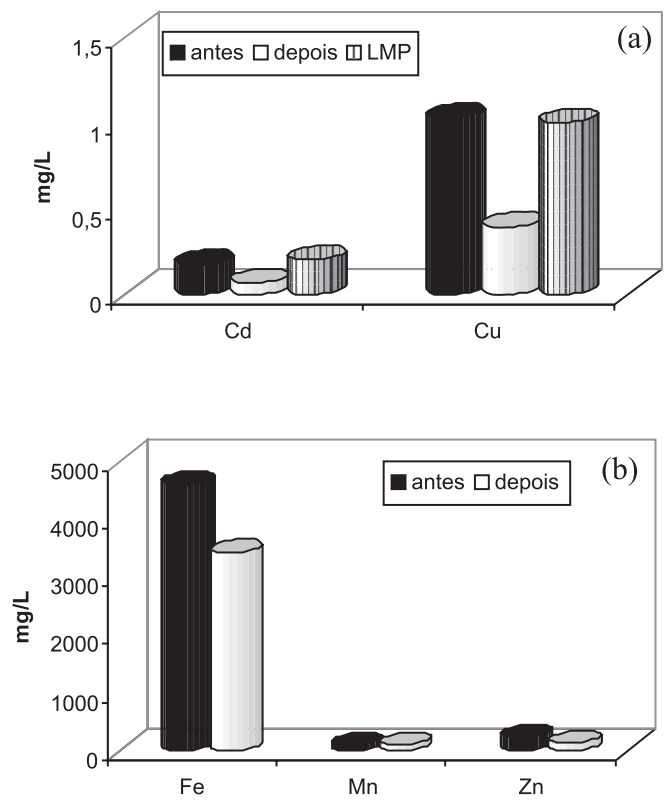

Figura 6. Concentração dos íons metálicos antes e depois do tratamento da água ácida da pilha de rejeitos com material zeolítico. (a) concentração inicial 0,17 - 1,0 $\mathrm{mg} \mathrm{L}^{-1}$; (b) concentração inicial $102-4608 \mathrm{mg} \mathrm{L}^{-1}$; LMP = limite máximo permissível para efluentes

Embora os resultados do tratamento da água ácida da pilha de rejeitos com zeólita por processo em leito móvel não tenham sido satisfatórios, este processo não pode ser totalmente descartado porque o material provém de matéria-prima abundante e de custo aquisitivo zero que, por si só, se constitui em um resíduo poluidor se não for reciclado. A zeólita sintética, pelas suas características de agente neutralizador e adsorvedor, poderá ser usada nas fases finais de outros processos de tratamento em diques ou como substrato de bacias de decantação.

Uma outra sugestão para tratamento destas águas residuárias com zeólita é por processo contínuo com colunas de percolação em série, onde o efluente da coluna 1 torna-se o influente da coluna 2 e assim por diante, até o efluente apresentar os níveis de descarte exigidos pela legislação vigente.
Por outro lado, a alta concentração do $\mathrm{Fe}^{3+}$ deve dificultar também a utilização dos tratamentos convencionais por precipitação. A pedra calcária é rapidamente coberta com o precipitado de hidróxido férrico, inibindo novas neutralizações e reduzindo drasticamente a eficiência do tratamento. No caso do uso de lima e outros materiais alcalinizantes, um cuidado constante para o uso de uma dose apropriada seria necessário porque se aplicada em excesso podem prejudicar a qualidade do efluente. Já o material zeolítico pode ser aplicado em excesso sem acarretar problemas.

A zeólita saturada de contaminantes após o tratamento dos efluentes de mineração pode ser descartada em aterro comum como resíduo classe II ou III, conforme as normas ABNT-NBR 10005 e 10006, já que as fortes forças responsáveis pela adsorção impedem a lixiviação dos íons metálicos no lençol freático ou em águas superficiais da área. Outra alternativa é a regeneração do adsorvedor após contato com $\mathrm{NaCl} 2 \mathrm{~mol} \mathrm{~L}^{-1}$ por processo de dessorção. O processo de dessorção é também muito importante economicamente, pois auxilia no tratamento da vida útil do adsorvedor e permite a obtenção de uma solução concentrada dos íons metálicos, que poderão ser usados como matéria-prima em algum processo produtivo. O tratamento proposto permitiu um ciclo de adsorção e regeneração de até 3 vezes no processo de leito móvel de $\mathrm{Zn}^{2+} 327 \mathrm{mg} \mathrm{L}^{-1}$ (adsorção $>80 \%$ e regeneração de 87 a 100\%) e a recuperação de $85 \%$ de $\mathrm{Zn}^{2+}$ de efluente de galvanoplastia ${ }^{25,27}$.

Na ação da gestão ambiental de complexos carboelétricos, além da utilização do material zeolítico em processo de leito móvel para tratamento dos efluentes ácidos, o adsorvedor poderá ser empregado das seguintes maneiras: em processos de leito fixo; como barreira reativa; no polimento de efluente de outro sistema passivo; colocado dentro de sacos permeáveis que podem ser removidos após o tratamento.

\section{CONCLUSÃO}

Os resultados demonstraram que a água piritosa de mina pode ser eficientemente descontaminada pelo processo de troca iônica se usando zeólita sintetizada a partir de cinzas de carvão, geradas na própria região carbonífera, como adsorvedor de baixo custo. $\mathrm{O}$ efluente tratado se apresentou adequado para ser lançado em corpos receptores, conforme as regulamentações em vigor. Em conjunto com o processo de troca iônica, o processo de precipitação aumentou a eficiência da remoção dos íons metálicos, já que um drástico aumento do pH foi induzido pela adição da zeólita (de 3 a 5).

Os altos níveis de poluição da água ácida da pilha de rejeitos fazem com que o tratamento mais apropriado com material zeolítico seja em sistemas secundários, terciários ou em colunas em série.

A mitigação dos impactos ambientais e dos prejuízos à saúde humana, causados pela atividade de usinas termelétricas a carvão, com a transformação de um rejeito poluidor em matéria-prima de um produto aplicável no tratamento dos efluentes líquidos da própria usina é a grande contribuição do presente estudo. A adoção desta prática na gestão ambiental das usinas termelétricas justificase por acarretar uma redução de ônus ambientais (legislação), sociais (saúde da comunidade) e comerciais (colaboradores, investidores, clientes, etc).

\section{AGRADECIMENTOS}

Ao Conselho Nacional de Desenvolvimento Científico e Tecnológico - CNPq pelo apoio financeiro, à Carbonífera do Cambuí Ltda. pelas amostras de efluentes e Dra. E. S. K. Dantas e MSc. M. E. B. Cotrim pelas análises de ICP-AES. 


\section{REFERÊNCIAS}

1. Nascimento, F. M. F.; Mendonça, R. M. G.; Macêdo, M. I. F.; Soares, P. S. M.; Resumos do I Congresso Brasileiro de Mina a Céu Aberto \& II Congresso Brasileiro de Mina Subterrânea, Belo Horizonte, Brasil, 2002.

2. Filion, M. P.; Siroois, L. L.; Ferguson, K.; CIM Bull. 1990, 83, 33.

3. Sasowsky, I.; Foos, A.; Miller, C.; Water Res. 2000, 34, 2742.

4. Mckinnon, W.; Choung, J. W; Xu, Z.; Finch, J. A.; Environ. Sci. Technol. 2000, 34, 2576

5. Macêdo, M. I. F.; Resumos do Encontro Nacional de Química Analítica, São Luís, Brasil, 2003.

6. Maschio, J.; Folha de São Paulo, São Paulo, Caderno Cotidiano, 21 de novembro de 2004, p. C5.

7. Ministério do Meio Ambiente. Resolução CONAMA n 357 de 17 de Março de 2005, http://www.mma.gov.br/port/conama/index.cfm, acessada em Abril 2006.

8. http://www.wvu.edu/\%7Eagexten/landrec/chemtrt.htm, acessada em Junho 2005.

9. Gazea, B.; Adam, K.; Kontopoulos, A.; Miner. Eng. 1996, 9, 23.

10. Xu, C. Y.; Schwartz, F. W.; Samuel, J. T.; Environ. Eng. Sci. 1997, 14, 141.

11. Webster, J. G.; Swedlund, P. J.; Webster, K. S.; Environ. Sci. Technol. 1998, 32,1361 .

12. Deorkar, N. V.; Tavlarides, L. L.; Environ. Prog. 1998, 17, 120.

13. Mohan, D.; Chander, S.; Colloids Surf., A 2001, 177, 183.

14. Feng, D.; Deventer, J. S. J.; Aldrich, C.; Sep. Purif. Technol. 2004, 40, 61.

15. Lin, C. F.; His, H. C.; Environ. Sci. Technol. 1995, 29, 1109.

16. Singer, A.; Berkgaut, V.; Environ. Sci. Technol. 1995, 29, 1748

17. Amrhein. C.; Haghnia, G .H.; Kim, T .S.; Mosher, P. A.; Gagajena, R. C.; Amanios, T.; Torre, L.; Environ. Sci. Technol. 1996, 30, 735.

18. Shih, W-H.; Chang, H-L.; Mater. Lett. 1996, 28, 263.

19. Steenbruggen, G.; Hollman, G. G.; J. Geochem. Explor. 1998, 62, 305.

20. Lee, M .G.; Yi, G.; Ahn, B-J.; Roddick, F.; Korean J. Chem. Eng. 2000, 17,325 .
21. Querol, X.; Plana, F.; Alastuey, A.; Lopez-soler, A.; Medinaceli, A.; Valero, A.; Domingo, M. J.; Garcia-rojo, E.; Fuel 2001, 80, 857.

22. Scott, J.; Guang, D.; Naeramitmarnsuk, K.; Thabuot, M.; J. Chem. Technol. Biotechnol. 2002, 77, 63.

23. Juan, R.; Hernandez, S.; Querol, X.; Andrés, J. M.; Moreno, N.; J. Chem. Technol. Biotechnol. 2002, 77, 299.

24. Querol, X.; Moreno, N.; Umaña, J. C.; Alastuey, A.; Hernández, E.; Lópezsoler, A.; Plana, F.; Int. J. Coal Geol. 2002, 50, 413.

25. Fungaro, D. A.; Silva, M. G.; Quim. Nova 2002, 25, 1081.

26. Fungaro, D. A.; Flues, M. S-M; Celebroni, A. P.; Quim. Nova 2004, 27, 582.

27. htpp://www.meiofiltrante.com.br, acessada em Junho 2005.

28. Fungaro, D. A.; Izidoro, J. C.; Almeida, R. S.; Ecl. Quim. 2005, 30, 31.

29. Henmi, T.; Clay Sci. 1987, 6, 277.

30. Aguiar, M. R. M. P.; Novaes, A. C.; Quim. Nova 2002, 25, 1154

31. Gurses, A.; Karaca, S.; Dogar, C.; Bayrak, R.; Açikyildiz, M.; Yalçin, M.; J. Colloid Interface Sci. 2004, 269, 310.

32. Faust, S. D.; Aly, O. M.; Adsorption Process for Water Treatment, Butterworths: London, 1987.

33. Perrich, J. R.; Actived Carbon Adsorption for Waste Water Treatment, CRC Press: Boca Raton, 1981.

34. Giles, C. H.; Smith, D.; J. Colloid Interface Sci. 1974, 47, 755.

35. Karcher, S.; Kornmuller, A.; Jekel, M.; Dyes Pigm. 2001, 51, 111.

36. Hall, K. R.; Eagleton, L. C.; Acrivos, A.; Vermeulen, T.; Ind. Eng. Chem. Fundam. 1966, 5, 212.

37. Helby, W. A.; Chem. Eng. 1952, 59, 153.

38. Moreno, N.; Querol, X.; Ayora, C.; Alastuey, A.; Fernández-Pereira, C.; Janssen-Jurkovicová, M.; J. Environ. Eng. 2001, 127, 994.

39. Moreno, N.; Querol, X.; Ayora, C.; Alastuey, A.; Fernández-Pereira, C.; Janssen-Jurkovicová, M.; Environ. Sci. Technol. 2001, 35, 3526.

40. Dyer, A. Em Zeolites surfaces and reactivity; Vaughan, D. J.; Patrick, R. D. A., eds.; Chapman and London: U.K, 1995, p. 333-354. 